\title{
Study on the deformation regulation of high speed road crossed by new small clear distance double line subway tunnel
}

\author{
ZHENG Aiyuan ${ }^{1, a}$ \\ ${ }^{1}$ Shenzhen Metro CO., LTD, Shenzhen, 518026, China \\ ahssdu@163.com
}

\begin{abstract}
Keywords: numerical simulation; undercrossing tunnel; field monitoring; surface deformation law. Abstract. As the development of urban city, the traffic problem becomes increasingly severe, and metro tunnel is a effective method to solve this problem. However, the influence of underground tunnel construction towards existing structure cannot be ignored. For this purpose, based on the Shenzhen metro line 7 project and its section underneath the Guangshen highway, the essay, through FLAC3D numerical simulation software, aims at the tunnel construction in upper-soft lower-hard ground and research on the deformation law of highway surface influenced by full-section grouting reinforcement and bench method. In order to ensure the accuracy of numerical simulation, make comparison between simulation data and field monitoring data.
\end{abstract}

\section{Introduction}

With the development of the city, the problem of traffic congestion is becoming more and more serious, people have to turn their attention to the development of underground space, but the more urgent need to solve the traffic problem areas, the more types of structures that ground is often distributed. Subway crossing under the existing structure of the building is more and more common, how to ensure that under the tunnel construction the security of the existing structure, the normal use of the current become the technical problems have to face. In order to solve this problem, the control of surface subsidence deformation is the most important. The main research methods include numerical simulation and model experiment [1-6]. On the other hand, the study of the settlement law caused by the peck formula and other theoretical methods to predict the settlement of the tunnel is also obtained. Such as Wei Gang et al have done a lot of work on the optimized application of the peck formula, and have done a lot of work on the value of the parameters and the scope of application [7-10]. The construction of the tunnel is a comprehensive project with many influencing factors. The settlement and deformation of the surface are related to the strata parameters, construction methods and reinforcement measures. This paper relies on one metro tunnel undercrossing the high-speed construction section, through the numerical simulation method, aiming at the tunneling engineering of the upper and lower strata under the action of the whole section grouting reinforcement and the upper and lower step method, study the deformation law of the expressway surface subsidence.

\section{Numerical Model and Method}

According to one new subway tunnel construction undercrossing one high-speed road, a 3D numerical model is used to simulate the construction of subway tunnel.

\section{Numerical Model}

According to the engineering drawings, the influence range of excavation is fully considered, and the hexagonal region with length of $56 \mathrm{~m}$ (Y direction), width of $199.7 \mathrm{~m}$ (X direction) and height of $50 \mathrm{~m}$ ( $\mathrm{Z}$ direction) is selected to establish the three-dimensional finite element model. The hexagonal elements are used for meshing, the number of cells is 41256 , and the number of nodes is 44962. The roadbed width is $36 \mathrm{~m}$, and the elastic yield criterion is adopted. After the simulation is started, the vertical pressure of $20 \mathrm{kN}$ is applied. The Mohr-Coulomb yield criterion is adopted in the soil, and the influence of groundwater is not considered. A two-meter area is reserved around the tunnel as a full-section grouting boundary. The initial structure of the tunnel is elastic and has a thickness of $200 \mathrm{~mm}$. The model is shown in Figure 1. 


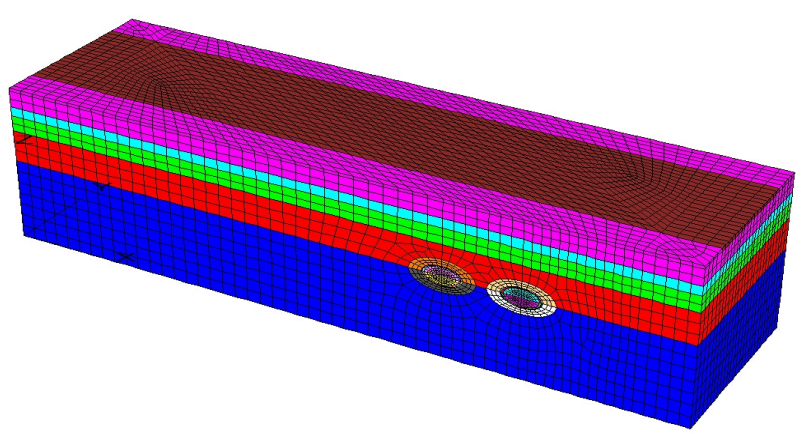

Fig.1 Numerical calculation model

\section{Mechanical Parameters Selection}

The mechanical parameters of each part are shown in Table 1.

Table 1 Mechanical parameters of different constructions

\begin{tabular}{|c|c|c|c|c|c|c|c|}
\hline \multirow[b]{2}{*}{ Item } & \multirow[b]{2}{*}{$\begin{array}{l}\text { Elasticity } \\
\text { modulus } \\
\text { /(MPa) }\end{array}$} & \multirow[b]{2}{*}{$\begin{array}{l}\text { Poiss } \\
\text {-on's } \\
\text { ratio }\end{array}$} & \multirow[b]{2}{*}{$\begin{array}{c}\text { natural unit } \\
\text { weight/ } \\
\left(\mathrm{kN} / \mathrm{m}^{3}\right)\end{array}$} & \multicolumn{2}{|c|}{ Direct fast cut } & \multirow[b]{2}{*}{$\begin{array}{l}\text { Thick-ne } \\
\text { ss /(m) }\end{array}$} & \multirow[b]{2}{*}{$\begin{array}{c}\text { Model } \\
\text { type }\end{array}$} \\
\hline & & & & $\begin{array}{c}\text { Cohesion } \\
(\mathrm{kPa})\end{array}$ & $\begin{array}{l}\text { internal } \\
\text { friction } \\
\text { angle }\end{array}$ & & \\
\hline Plain fill & 8.98 & 0.35 & 18.7 & 10 & 12 & 6 & $\mathrm{M}-\mathrm{C}$ \\
\hline $\begin{array}{c}\text { Gravel sticky } \\
\text { soil }\end{array}$ & 10.40 & 0.32 & 18.3 & 26 & 28 & 3 & $\mathrm{M}-\mathrm{C}$ \\
\hline $\begin{array}{l}\text { Weathered } \\
\text { granite }\end{array}$ & 14.00 & 0.30 & 18.7 & 28 & 30 & 5 & $\mathrm{M}-\mathrm{C}$ \\
\hline $\begin{array}{l}\text { Strongly } \\
\text { weathered } \\
\text { granite }\end{array}$ & 20.4 & 0.30 & 19 & 30 & 34 & 10 & $\mathrm{M}-\mathrm{C}$ \\
\hline $\begin{array}{l}\text { Weathered } \\
\text { granite }\end{array}$ & 56.00 & 0.27 & 27.0 & 60 & 60 & 26 & $\mathrm{M}-\mathrm{C}$ \\
\hline $\begin{array}{c}\text { Upper } \\
\text { grouting ring }\end{array}$ & 53.10 & 0.30 & 27.0 & 50 & 51 & - & M-C \\
\hline $\begin{array}{l}\text { Lower } \\
\text { grouting ring }\end{array}$ & 70.30 & 0.30 & 27.0 & 66 & 63 & - & M-C \\
\hline $\begin{array}{l}\text { Early support } \\
\text { structure }\end{array}$ & $3.45 \mathrm{e} 3$ & 0.2 & - & - & - & 0.26 & ELA \\
\hline
\end{tabular}

\section{Numerical Method}

In order to simplify the model, the highway is built by the elastic unit and $20 \mathrm{kPa}$ road load is applied to the surface of the highway model to simulate the traffic condition of the expressway. And, tunnel excavation is simulated through unit life and death simulation. The tunnel is a double-hole circular tunnel, the two lines are parallel to each other, using the upper and lower step excavation, lower step lag behind upper step on a construction step. Double-hole tunnel excavation are the non-synchronous excavation, the left tunnel is excavated first, leading the right line tunnel about 4 construction steps, that is to say, the left tunnel on the fourth ring and the right tunnel on the first ring are on the excavation at the same time, one construction footage is $4 \mathrm{~m}$ long.

\section{Calculation Result Analysis}

Figure 3 shows the road subsidence after completing the excavation of the tunnel, the general trend of road settlement can be obtained from the figure. It can be seen that: (1) the direction of the road sedimentation tank extends is the same direction as the tunnel axis; (2) the center of the road sedimentation tank and the two-lane tunnel center do not coincide, to the first tunnel offset; (3) Pavement subsidence caused by excavation of two-lane tunnel presents a single groove "V" shape, rather than the double groove "W" shape; (4) the settlement at the boundary of the model and the sedimentation tank width are slightly larger than the other positions. The law of road settlement is analyzed as follows. 


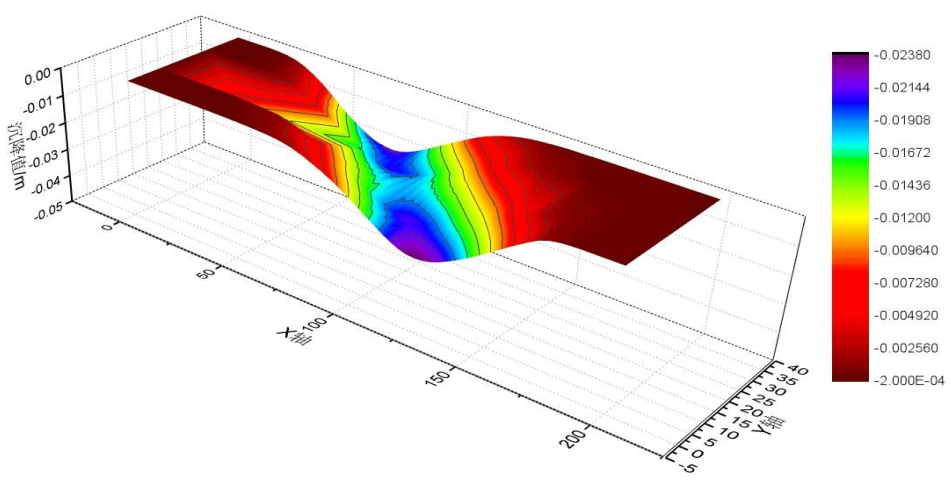

Fig. 2 3D cloud picture of stratum settlement

In order to verify the validity of the numerical calculation, the numerical results are compared with the actual test. As shown, it can be seen that both have the same trend, specific analysis is as follows: (1) the deformation trend of measuring points in two figure is roughly same, the early stage of the excavation effect on measuring point is small, basic stability, settlement, in accordance with the tunnel excavation in settlement of a rapid development period, and then the deformation stability returns again, on the whole settlement development present " $\mathrm{Z}$ " form;(2) to compare the two figure, each measuring point settlement development stable value is basically the same, there are differentiation phenomenon, a relatively large part of the measuring point subsidence, $\mathrm{S} / \mathrm{b}$ the picture $\mathrm{Xtt10}+780 \sim 795$ settlement is bigger, about 30 to $35 \mathrm{~mm}$, while $\mathrm{S} / \mathrm{Xtt} 10+805 \sim 815$ settlement is small, about $5 \sim 10 \mathrm{~mm}$, have a point in a graph with similar;(3) b figure some stations of small and medium-sized settlement value in between them, and no obvious corresponding simulation results in a figure, may be due to the limited field testing data, settlement of target point is not yet stable, late may continue to develop.

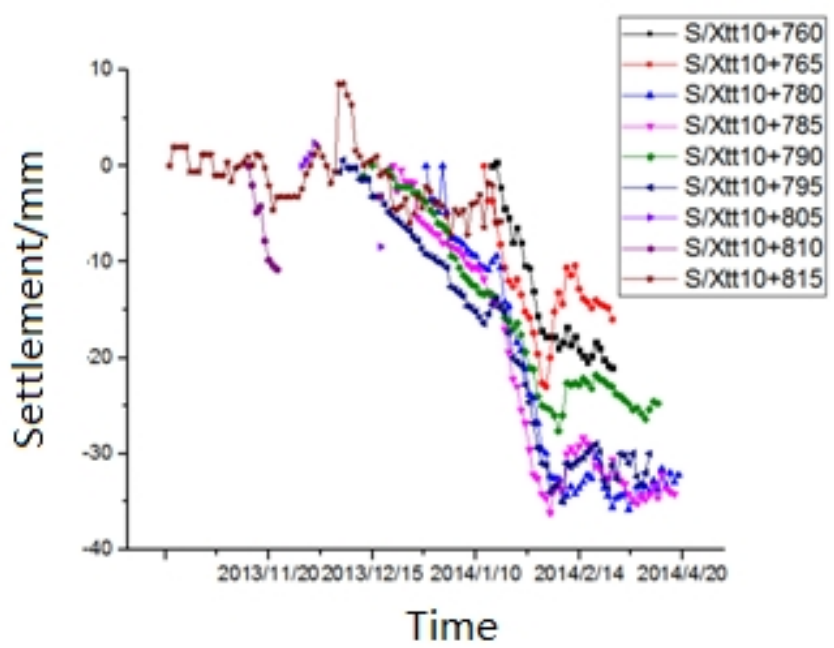

Fig.3 Curve of right line vault settlement

\section{Conclusions}

This paper based on one metro line undercrossing a highway section, using FLAC3D simulation software, for tunnel construction under the soft substratum formation ,and the surface subsidence deformation law of the highway under the influence of whole section grouting reinforcement and up and down step method is studied. It can be seen from the analysis in this paper that the surface subsidence law of the underground tunnel under the subsurface of the upper soft subsurface has its remarkable characteristics, which is summarized as follows:

(1) Using flac3d finite difference software for metro tunnel excavation simulation, compare the results with the actual monitoring data, the trend has obvious similarities, both steady - development stable growth curve " $Z$ " form, and on the concrete numerical value, the gap between basic keep 
within $10 \%$, therefore, can be thought of as the numerical model can better reflect the vault, the place such as the surface subsidence.

(2) Undercrossing the double line tunnel construction to form the shape of the surface subsidence trough and tunnel span, in particular, when the channel spacing is small, the formation of two tunnels in the earth's surface subsidence trough will produce superimposed effect, form a "single groove" settlement.In the case of two holes, the surface will form a "W" double concave subsidence tank.

\section{References}

[1] Vega J, Fraile A, Alarcon E, et al. Dynamic response of underpasses for high-speed train lines[J]. Journal of Sound \& Vibration, 2012, 331(23):5125-5140.

[2] ZHAO Li-cai. Construction Techniques for a Shallow-Buried Long-Span Highway Tunnel in Soft Soil Passing Under the Subgrade of an Existing Railway Station[J]. Modern Tunnelling Technology, 2014(06): 160-166.

[3] LI Shu-cai, LI Ke-xian, et al. Study of blasting vibration and deformation control for metro construction beneath existing metro tunnel in short distance[J]. Rock and Soil Mechanics, 2014, 35(2): 284-289.

[4] SHI Yu-feng, YANG Jun-sheng, et al. Risk analysis and control study of super-shallow tunnel with large cross-section under water-rich channel[J]. Rock and Soil Mechanics, 2012, 33(2): 229-234

[5] C.W.W. Ng, M.A. Soomroc, Y. Honga. Three-dimensional centrifuge modelling of pile group responses to side-by-side twin tunnelling[J]. Tunnelling and Underground Space Technology, 2014. 43: 350-361

[6] ZHU Zheng-guo, HUANG Song, ZHU Yong-quan. Study of road surface settlement rule and controlled criterion for railway tunnel undercrossing highway[J]. Rock and Soil Mechanics, 2012, 33(2): 558-576.

[7] CHEN Chun-lai, ZHAO Cheng-li, WEI Gang, DING Zhi. Prediction of soil settlement induced by double-line shield tunnel based on Peck formula[J]. Rock and Soil Mechanics. 2014, 35(8): 2212-2218

[8] WEI Gang. Prediction of soil settlement caused by double-line parallel shield tunnel construction[J]. Disaster Advances, 2013, 6(6): 23-27.

[9] WEI Gang. Study on calculation for width parameter of surface settlement trough induced by shield tunnel[J]. Industrial Construction, 2009, 39(12): 74-79, 109.

[10] WEI Gang. Selection and distribution of ground loss ratio induced by shield tunnel construction[J]. Chinese Journal of Geotechnical Engineering, 2010, 32(9): 1354-1361. 